\title{
Evaluasi Penerapan Hazard Analysis Critical Control Point (HACCP) pada Mutu Daging $S e$ 'i Babi di Kota Kupang
}

\section{Evaluation of The Application of Hazard Analysis Critical Control Point (HACCP) to The Qualty of Pork Se'i Meat in Kupang City}

\author{
E. S. D. C. Cruz*, H. J. D. Lalel, dan P. R. Kale \\ Program Pascasarjana, Program Studi Ilmu Peternakan \\ Universitas Nusa Cendana, Jl. Adisucipto, Kupang, NTT 85001 \\ *E-mail: esmeniacruz294@gmail.com
}

(Diterima: 26 Juni 2018; Disetujui: 4 Agustus 2018)

\begin{abstract}
ABSTRAK
Daging se'i (daging asap) merupakan produk olahan tradisional yang popular di NTT proses pembuatan se' $i$ dari bahan daging babi dan sapi. Sistem pengolahan se' $i$ masih menggunakan cara yang tradisional dan konvensional. Untuk memproduksi produk pangan yang aman dikonsumsi, perlu menggunakan standar-standar keamanan pangan. Salah satu standar keamanan pangan yang diakui adalah Hazard Analysis and Critical Control Point (HACCP). Tujuan penelitian ini adalah untuk mengetahui proses pembuatan $s e^{\prime} i$ di 2 Depot se' $i$ yang berada di kawasan Kota Kupang berdasarkan HACCP selama periode waktu Januari-April 2018 dengan analisis deskriptif. Hasil yang diperoleh di kedua Depot $s e$ ' $i$ belum menerapkan standar HACCP, SSOP dan proses GMP, sehingga ada potensi bahaya dari aspek biologis, fisik dan kimia. Dari identifikasi CCP ditetapkan 5 proses yang memiliki CCP, yaitu: penerimaan daging, pengirisan, pencampuran bumbu, pengasapan dan penyimpanan. Perlu menerapkan HACCP untuk menunjang produksi se' $i$. Rekomendasi untuk HACCP, SSOP dan GMP adalah; higienes karyawan, pemeriksaan alat produksi secara berkala, perbaikan tata ruang dan keamanan air.
\end{abstract}

Kata kunci: GMP, HACCP, Se'i, SSOP

\section{ABSTRACT}

Se'i meat (bacon) is a traditional processed product that popular in NTT se'i processing of pork and beef. Se'i processing system still uses traditional and conventional way. To produce food products that are safe to consume, it is necessary to use food safety standards. One of the recognized food safety standards is the Hazard Analysis and Critical Control Point (HACCP). The objaective of this research is to know how to process of se' $i$ in 2 Depot se' $i$ located in Kupang City area based on HACCP during period of January-April 2018 with descriptive analysis. The results obtained in both Depot se'i have not implemented HACCP, SSOP and GMP standards, so there is potential danger from biological, physical and chemical aspects. From the identification of CCP, there are 5 processes that have CCP, that is: meat acceptance, slicing, mixing seasoning, fumigation and storage. Need to apply HACCP to support se'i production. Recommendations for HACCP, SSOP and GMP are; hygienic employees, periodic inspection of production equipment improvement of spatial and water security.

Keywords: GMP, HACCP, Se'i, SSOP

\section{PENDAHULUAN}

Daging merupakan bahan makanan yang mudah mengalami penurunan mutu akibat proses mikrobiologis, kimia dan fisik. Sifat daging yang cepat mengalami kerusakan, akan mengakibatkan daging sulit diperoleh dalam keadaan segar di tempa-tempat yang jauh dari pusat produksi sehingga usaha pengolahan dan pengawetan sangat diperlukan. Fenomena inilah yang menjadi dasar bagi masyarakat Timor di Nusa 
Tenggara Timur (NTT) untuk mengupayakan suatu bentuk pengawetan yang masih bersifat tradisional dengan cara pengasapan menjadi daging $s e^{\prime} i$. Daging babi yang diasap sangat disukai terutama rasanya yang khas.

Pembusukan daging dapat disebabkan oleh aktivitas enzim-enzim dalam daging (autolisis), kimiawi (oksidasi) dan mikroorganisme. Mekanisme pembusukan ini sangat kompleks. Faktor-faktor yang mempengaruhi pertumbuhan mikroorganisme pada daging adalah: jenis dan jumlah mikroorganisme awal (pencemar) serta penyebarannya, sifat fisik daging, sifat kimiawi daging, ketersediaan oksigen, serta suhu. Konsentrasi komponen tersebut dalam daging dan penggunaannya oleh jenis mikroba tertentu yang akan menentukan waktu terjadinya (onset) dan jenis pembusukan (Lukman, 2010). Kerusakan pada daging disebabkan oleh terjadinya oksidasi lemak dan juga karena bakteri yang mempengaruhi kualitas daging (Malelak et al., 2017).

Daging se'i merupakan salah satu produkan daging sapi, babi dan daging rusa. Cara pengolahan daging se' $i$ babi sederhana, hal ini yang menyebabkan banyaknya masyarakat Kupang menjual daging se' $i$ babi. Pertumbuhan mikroba pada daging dipicu dari sifat daging itu sendiri seperti kadar air, pH, protein, lemak, karbohidrat, dan vitamin (Suardana dan swacita, 2009). Kerusakan daging oleh mikroba mengakibatkan penurunan mutu daging. Besarnya kontaminasi mikroba pada daging menentukan kualitas dan masa simpan daging (Usmiati, 2010).

$\mathrm{Se}^{\prime} i$ dalam proses pembuatannya memiliki banyak kemungkinan bahaya biologis, seperti cemaran mikroba, bahaya fisik adanya debu-debu dan serpihan kayu, bahaya kimia akibat arang, atau proses produksi selama pembuatan $s e ' i$ berlangsung. Semua hal tersebut dapat terjadi, namun juga dapat dikendalikan. Keamanan pangan merupakan persyaratan utama dan terpenting dari seluruh parameter mutu pangan yang ada. Saat ini konsumen menyadari bahwa mutu pangan khususnya keamanan pangan tidak dapat hanya dijamin dengan hasil uji produk akhir dari laboratorium. Mereka berkeyakinan bahwa produk yang aman didapat dari bahan baku yang ditangani dengan baik, diolah dan didistribusikan dengan baik akan menghasilkan produk akhir yang bermutu dan aman (Kementrian Perindustrian RI, 2010).

Standar-standar keamanan pangan sangat diperlukan untuk jaminan memproduksi pangan yang aman (Badan Standarisasi Nasional, 1998). Salah satu standar keamanan pangan yang diakui adalah Hazard Analysis and Critical Control Point (HACCP). HACCP merupakan suatu piranti (sistem) yang digunakan untuk menilai bahaya dan menetapkan sistem pengendalian yang memfokuskan pada pencegahan. HACCP diterapkan pada seluruh mata rantai proses pengolahan produk pangan (Thaheer, 2005).

HACCP merupakan program persyaratan dasar untuk cara produksi makanan yang baik (Good Manufacturing Practice, GMP) atau praktek higiene yang baik (Good Hygiene Practice, GHP) yang akan dipatuhi oleh semua pelaku bisnis makanan, yang memiliki reputasi baik untuk memastikan bahwa makanan yang diberikan pada konsumen adalah makanan yang sehat dan aman (Prasetyo, 2000).

Sistem HACCP juga menjadi suatu sistem manajemen mutu yang berfungsi sebagai kerangka acuan yang didalamnya setiap kegiatan proses dapat dikelola (Nurmawati, 2012). Maka dari itu, untuk meningkatkan keamanan pangan pada proses pembuatan se' $i$ ini diperlukan pengamatan dan penerapan HACCP. Pengamatan dan penerapan ini diharapkan mampu mengidentifikasi, menganalisis serta mengendalikan bahaya yang mungkin terjadi pada proses pembuatan $s e^{\prime} i$.

Se'i yang banyak diminati oleh
wisatawan baik domestik maupun
internasional. Sebagai salah obyek kuliner
yang perlu dijaga mutu dan keamananya
Untuk itu dibutuhkan suatu analisa untuk

Evaluasi Penerapan Hazard Analysis ... (Cruz et al.) 
mengidentifikasi bahaya yang terkait selama proses pembuatan $s e^{\prime} i$ serta memberikan rekomendasi untuk mengembangkan sistem HACCP sehingga menghasilkan produk yang aman untuk dikonsumsi. Dengan produk se'i yang aman maka produk ini akan dapat bersaing di pasaran serta akan memperkuat potensinya dalam pertumbuhan ekonomi nasional. Berdasarkan latar belakang di atas, maka perlu untuk mengidentifikasi bahaya yang terkait selama proses pembuatan se'i serta memberikan rekomendasi untuk mengembangkan sistem HACCP, sehingga menghasilkan produk yang aman.

\section{METODE}

Pendekatan masalah dilakukan dengan cara melakukan pengamatan langsung di lapangan, kunjungan pada Depot se'i babi, mempelajari sistem mutu dan keamanan pangan yang diterapkan serta seberapa jauh jaminan atas keamanan pangan diberikan oleh sistem atau pengawasan mutu dan keamanan yang telah diterapkan. Ditentukan titik-titik kritis dalam proses produksi, dan dilakukan identifikasi bahaya yang dapat terjadi serta pencegahan yang dapat dilakukan. Penetapan lokasi sampel untuk penelitian dilakukan secara purposif dengan pertimbangan jumlah sampel lokasi dari 5 lokasi yang memenuhi persyaratan dan 2 lokasi (40\%) yang di pilih sebagai lokasi penelitian, pada dua depot $s e^{\prime} i$ babi, yang telah berjalan lebih dari 5 tahun dan menghasilkan produk yang hampir sama, satu depot se'i babi terletak di Kecamatan Oebufu Kupang (X), dan satu depot se'i babi terletak di Kecamatan Maulafa (Y). Penelitian dilakukan dengan melakukan kunjungan pada unit produksi, wawancara pada personil yang bertanggung jawab pada unit prosesing, pengamatan proses produksi, pengambilan sampel contoh se'i dari titik kritis dalam mata rantai produksi. Contoh se'i dianalisa terhadap cemaran mikroba, total plate count (TPC), adanya bakteri Bakteri E. Coli dan Salmonela Aureaus, uji kemis ( nitrit) serta uji cemaran fisik ( $\mathrm{Pb}$ dan $\mathrm{Mn})$.

\section{Uji Angka Lempeng Total}

Sampel ditimbang $1 \mathrm{~g}$ kemudian dihaluskan. BPW dimasukan kedalam empat tabung reaksi yang masing-masing diisi $9 \mathrm{ml}$. Daging se' $i$ babi yang yang telah dihaluskan dimasukan kedalam BPW tabung reaksi pertama sebagai pengeceran $10^{-1}$ selanjutnya dilakukan pengeceran hingga $10^{-4}$. Setiap pengeceran dipipet sebayak $1 \mathrm{ml}$ dan dituangkan kecawan petri steril kemudian dituankan media NA cawan petri diinkubasi selama 24 jam pada suhu $37{ }^{\circ} \mathrm{C}$ setelah itu dihitung jumlah koloni (SNI 2897, 2008).

\section{Uji kuantitatif $\boldsymbol{E}$. Coli}

Sebanyak 10 gr sampel dihaluskan kemudian dimasukan kedalam wadah plastik steril dan ditambahkan $90 \quad \mathrm{ml}$ larutan Buuterfields PhosphateBuffered dan dihomogenkan selama 2 menit dengan Stomacher (pengenceran $10^{-1}$ ) selanjutnya dilakukan pengenceran berseri hingga $10^{-}$ ${ }^{3}$. Sampel dipipet sebanyak $1 \mathrm{ml}$ dari setiap pengeceran kedalam masing-masing 3 seri tabung LB yang berisi tabung durham. Diinkubasikan kembali selama 24 jam. Tabung positif ditandai dengan kekeruhan dan gas dalam tabung durham. Tabung LB positif diinokulasikan kedalam media $E C$ broth yang yang berisi tabung durham diinkubasi selama 24 jam pada suhu $40^{\circ} \mathrm{c}$ yang menghasilkan gas dipisahkan. Tabung positif ditandai dengan kekeruhan dan gas dalam tabung durham. Jumlah tabung yang positif ditentukan berdasarkan angka paling memungkinkan (APM) (SNI 01-2332, 2006).

\section{Uji Kuantitatif $S$. aureus}

Sampel ditimbang 60 gr dalam kantong plastik dan ditambahkan $90 \mathrm{ml}$ larutan BPB sehingga diperoleh pengenceran $10^{-1}$ kemudian dimasukan kedalam stomacher kecepatan $250 \mathrm{rpm}$ selama 15 detik. Larutan sampel dari pengeceran $10^{-1}$ dipipet $1 \mathrm{ml}$ ke dalam tabung reaksi berisi $9 \mathrm{ml}$ BPB sehingga memperoleh pengenceran $10^{-2}$. Larutan sampel dari masing-masing pengenceran dipipet $1 \mathrm{ml}$ ke cawan petri steril. Media Baird Parke Agar (BPA) dituangkan ke masing-masing cawan 
Tabel 1. Pemilihan Bahan Baku Daging

\begin{tabular}{|c|c|c|}
\hline Tahapan Proses & Aktual & Standard \\
\hline Pembelian Daging Segar & $\begin{array}{l}\text { Pembelian bahan baku (daging } \\
\text { babi) di Depot X, daging babi } \\
\text { dibeli dari petani peternak tampa } \\
\text { memperhatikan kehigienisan, serta } \\
\text { tidak mempelajari asal bahan baku } \\
\text { tersebut. Di Depot Y daging babi } \\
\text { dibeli di Rumah Potong Hewan } \\
\text { (RPH). }\end{array}$ & $\begin{array}{l}\text { - Memiliki Checklist } \\
\text { pembelian bahan makanan } \\
\text { - Membeli di tempat pembelian } \\
\text { yang sudah disertifikasi oleh } \\
\text { badan yang bertanggung } \\
\text { jawab (melampirkan (CoA) }\end{array}$ \\
\hline
\end{tabular}

petri dan diratakan cawan petri diinkubasi secara terbaik pada suhu $40^{\circ} \mathrm{C}$ selama 48 jam cawan petri yang ditumbuhi 25-250 koloni Staphylococcus aureus dihitung. Koloni Staphylococcus aureus berwarna abu-abu sampai hitam mengkilat dengan lingkaran cerah disekelilinya dan seringkali lingkaran jernih, koloni mempunyai getah kental ketika. Disentuh dengan jarum Ose (Lutfi, 2014).

\section{Analisi kuantitatif nitrit}

Pemeriksaan nitrit dilakukan secara spektrofotometri dalam daging babi dan se'i babi dengan metode Griess secara spektrofotometri dengan menggunakan senyawa amina asam sulfanilamida dengan agen pengkopling N-1-naftiletilen-diamonium dihidroklorida (NEDA). (Habibah, 2018) Analisis cemaran logam berat $\mathrm{Pb}$ menurut Kohar (2005) adalah sebagai berikut 1) sampel dalam bentuk abu, lalu ditimbang $\pm 100 \mathrm{mg}$ kemudian. 2) sampel dilarutkan dalam $8 \mathrm{ml} \mathrm{HNO}_{3}$, $1 \mathrm{~N}$ lalu dilarutkan. 3) Agar sampel larut sempurna, sampel abu yang telah ditentukan dengan $\mathrm{HNO}_{3} 1 \mathrm{~N}$ dipanaskan pada suhu $60{ }^{\circ} \mathrm{C}-70{ }^{\circ} \mathrm{C}$ sampai larut sempurna. 4) sampel lalu disaring dengan kertas saring (Whatman/ditampung), kemudian 5) larutan sampel diukur/ diencerkan sampai $10 \mathrm{~m}$ (labu ukur) dengan $\mathrm{HNO}_{3}$ 1N. 6) sampel siap dinalisis dengan menggunakan alat AAS.

\section{HASIL DAN PEMBAHASAN}

Berdasarkan hasil penelitian melalui observasi dan wawancara yang dilakukan terhadap penerapan sistem menajemen mutu dan keamanan produk daging $s e^{\prime} i$ babi di produsen se' $i$ Depot X di Kecamatan Oebufu dan produsen se'i Depot Y di Kecamatan Maulafa, Kupang. Penelitian dimulai dari proses pemilihan bahan baku, pengirisan, curing, pencampuran bumbu, panggang dan penyimpanan.

\section{Analisis Pembuatan Se'i Babi (X) dan (Y)}

Observasi pertama yang dilakukan yaitu membandingkan proses pengolahan se' $i$ di lapangan dengan standar prosedur dari sumber pustaka. Pengamatan dilakukan pada semua tahap mulai dari bahan baku daging utuh sampai menjadi se' $i$.

Produsen Depot se'i $\mathrm{X}$ dan $\mathrm{Y}$ menggunakan daging babi yang masih segar (Tabel 1). Produsen se'i X membeli babi dari petani peternak yang berada di kawasan Kota Kupang. Sedangkan produsen se' $i$ Y membeli langsung dari Rumah Pemotongan Hewan (RPH) Oeba yang dibungkus dengan kantong plastik dan kemudian diangkut dengan mobil. Daging babi yang dipilih, untuk pembuatan $s e ' i$ daging yang masih segar, warna merah cerah, terdiri dari serat-serat bergaris melintang yang arahnya sejajar. Umumnya digunakan bagian topside, dan tetelan. Topside merupakan bagian pangkal kaki belakang. Bagian ini memiliki bentuk yang ramping, cukup lembut, dan mudah matang. Daging babi bagian mayang daging berwarna merah segar dan banyak bergajih (lemak). Bagian tetelan pada daging babi biasanya terdiri dari daging-daging yang melekat pada tulang. Daging yang melekat langsung pada tulang 
Tabel 2. Hasil penelitian pada tahapan Pengirisan dan pencampuran bumbu

\begin{tabular}{llll}
\hline Tahapan Proses & \multicolumn{1}{c}{ Aktual } & \multicolumn{2}{c}{ Standard } \\
\hline Pengirisan, Curing dan & Pengirisan, Curing dan pencampuran & $\bullet$ Tempat yang aman dan \\
Pencampuran Bumbu & bumbu dilakukan pada tempat yang & higienes & \\
& $\begin{array}{l}\text { terbuka dan tidak higienis serta } \\
\text { penambahan bumbu tidak berdasarkan }\end{array}$ & yang ada & \\
& pada takaran yang ada & & \\
\hline
\end{tabular}

Tabel 3. Hasil penelitian pada tahapan pengasapan atau panggang

\begin{tabular}{|c|c|c|}
\hline Tahapan Proses & Aktual & Standard \\
\hline $\begin{array}{l}\text { Pengasapan } \\
\text { daging } s e^{\prime} i\end{array}$ & $\begin{array}{l}\text { - Pengasapan dilakukan pada } \\
\text { tempat terbuka } \\
\text { - Masih ditemukan beberapa jenis } \\
\text { serangga ditempat pengasapan } \\
\text { - Se'i matang betul baru diambil }\end{array}$ & $\begin{array}{l}\text { - Sebaiknya tempat pengasapan tertutup } \\
\text { - Jarak bara kayu dengan para-para } \\
\text { tempat meletakan daging sekitar } 50 \text { - } \\
100 \mathrm{~cm} \\
\text { - Lama proses pengasapan sekitar } \pm 15 \text { - } \\
45 \text { menit }\end{array}$ \\
\hline
\end{tabular}

memiliki komposisi serat otot yang teksturnya cukup kenyal. Bagian tetelan sangat cocok digunakan untuk membuat se'i.

Proses pengirisan daging selebar \pm 2 jari dan setebal $\pm 3 \mathrm{~cm}$ tidak terlalu tebal dan tidak terlalu tipis, seragam, serta masih utuh dan memanjang (Tabel 2). Dalam proses pencampuran bumbu pada produsen $s e^{\prime} i$ Depot $\mathrm{X}$ kadang menggunakan zat pewarna dengan tujuan untuk memberi warna merah cerah pada daging dan memperpanjang umur simpang daging $s e^{\prime} i$ tersebut. Pada produsen $s e^{\prime} i$ Depot $Y$ proses pencampuran bumbu menggunakan rempah-rempah, garam, bawan dan gula. Curing merupakan proses perendaman daging yang telah diiris. Sebagai bahan untuk Curing adalah campuran antara garam dan garam saltpeter atau $\mathrm{NaNO}_{2} / \mathrm{KNO}_{3} /$ garam sendawa (jika ada) dengan formulasi umum garam (Nacl) sebanyak 1-2\% untuk $1 \mathrm{~kg}$ daging $( \pm$ 1 sendok makan) dan garam saltpeter 500/ $\mathrm{mg}$ atau $0,05 \%$ untuk $1 \mathrm{~kg}$ bahan/daging babi (Malelak et al., 2015). Bahan-bahan tersebut dilarutkan dengan air secukupnya dan dilakukan proses curing selama 6-12 jam. Setelah dilakukan proses curing daging diangkat, digantung untuk mengeluarkan air dari daging dan sisa-sisa darah selama 1-2 jam. Proses ini sangat penting sebab apabila daging yang tidak ditiriskan terlebih dulu tapi langsung diasapkan menghasilkan $s e^{\prime} i$ yang berwarna merah kehitaman. Berdasarkan hasil pengamatan di lapangan di temukan penyimpangan yaitu Pekerja tidak menggunakan alat pelindung diri (APD) lengkap selama proses pengirisan dan curing, seperti celemek, sarung tangan, penutup kepala dan tidak menggunakan sepatu boot. Hal tersebut dapat menyebabkan kontaminasi silang dari kulit atau kuku ke daging se' $i$.

Pada tahapan proses ini beberapa hal telah sesuai dengan standard HACCP yang ada seperti pengasapan daging se'i sudah benarbenar matang baru diangkat atau disajikan (Tabel 3). Kemudian telah dilakukan pula pemanggangan sesuai dengan suhu standar yaitu $\pm 15-45$ menit tergantung pada panas dan jarak api dengan daging. Selama pengasapan daging dibalik setiap 15 menit agar tidak hangus. Setelah diasap daging diangkat dan didinginkan (Costa, 2013). Namun demikian, tingkat kehigienisannya perlu ditingkatan dikarenakan pada tahapan ini ditemukan beberapa jenis serangga disekitar tempat pengasapan se'i. Berdasarkan pengamatan dilapangan tempat pengolahan se'i yang dilakukan oleh karyawan di Depot X dan Y kurang memperhatikan aspek hygiene seperti ditemukan tempat sampah yang tidak tertutup dan diletakan dekat dengan pengolahan $s e^{\prime} i$ 
Tabel 4. Hasil penelitian pada tahapan penyimpanan daging se' $i$

\begin{tabular}{lll}
\hline Tahapan Proses & \multicolumn{1}{c}{ Aktual } & \multicolumn{1}{c}{ Standard } \\
\hline Penyimpanan & - Masih ditemukan beberapa jenis serangga & - Fasilitas penyimpanan dalam \\
daging se' $i$ & di tempat penyimpanan bahan makanan & keadaan bersih, saniter dan \\
& - Sudah dilakukan pemisahan daging & dirawat dengan baik \\
& mentah dan matang & Suhu penyimpanan harus \\
& Penyimpanan se'i dalam wadah tertutup & $\begin{array}{l}\text { memenuhi persyaratan untuk } \\
\text { chiller: } 1{ }^{\circ} \mathrm{C}-4{ }^{\circ} \mathrm{C}\end{array}$ \\
\hline
\end{tabular}

Tabel 5. Deskripsi produk se'i babi

\begin{tabular}{ll}
\hline Parameter deskripsi & \multicolumn{1}{c}{ Keterangan } \\
\hline Nama produk & Daging $s e^{\prime} i$ babi \\
Komposisi & $\begin{array}{l}\text { Daging babi, garam, merica halus, garam nitrat atau } \\
\text { nitrit (saltpeter) }\end{array}$ \\
Karakteristik produk & Bentuk memanjang dengan panjang $30 \mathrm{~cm} \mathrm{dan}$ \\
& lebar $3 \mathrm{~cm}$. \\
Metode pengolahan & Pemanggangan \\
Pengemasan & Plastik PP \\
Kondisi penyimpanan & Suhu ruangan \\
Umur simpan & 1 minggu \\
Metode distribusi & Diantar dengan motor \\
\hline
\end{tabular}

(Tabel 4). Selain itu juga ditemukan karyawan melakukan tindakan kurang aman dengan tidak mencuci tangan sebelum mengolah makanan. Menurut standard HACCP tempat pembuangan sampah sisa hasil olahan diletakan jauh dari tempat pengolahan, agar tidak menjadi sumber kontaminasi silang.

Dari hasil observasi yang di lakukan awal kontaminasi mungkin berawal dari proses penyembelihan ternak babi yang ada di Kota Kupang (Tabel 5). Bahri (2008) mengatakan bahaya atau hazard yang berkaitan dengan keamanan pangan asal ternak dapat terjadi pada setiap matarantai mulai dari praproduksi di produsen, pasca produksi sampai produk tersebut didistribusikan dan disajikan kepada konsumen.

Identifikasi bahaya (mikrobiologi, kimia, dan cemaran logam berat)

Potensi bahaya yang berasal dari pengamatan di Depot $X$ dan $Y$ yang ada di Kota Kupang dapat dilihat pada Tabel 6.
Seluruh sampel (100\%) dari dua depot se'i (X dan Y) yang ada di Kota Kupang telah terkontaminasi mikroba melebihi standar yang ditetapkan oleh SNI yaitu $1 \times 10^{6} \mathrm{cfu} / \mathrm{g}$ (Tabel 7). Jumlah TPC daging segar yang tertinggi untuk depot $\mathrm{X}$ (sampel 4) yaitu sebesar $8,8 \times 10^{6} \mathrm{cfu} / \mathrm{gr}$ dan depot Y (sampel 1) yaitu sebesar $7,2 \times 10^{7} \mathrm{cfu} / \mathrm{g}$. Sedangkan untuk daging $s e^{\prime} i$, jumlah TPC yang tertinggi pada depot X (sampel 3) yaitu $9,1 \times 10^{4} \mathrm{cfu} / \mathrm{gr}$ dan depot Y (sampel 2) yaitu sebesar $9,5 \times 10^{3}$ $\mathrm{cfu} / \mathrm{g}$.

Sumber kontaminasi pada daging dapat berupa: hewannya sendiri (misalnya: rambut, bulu (unggas), kulit, kotoran, isi saluran pencernaan), air yang digunakan selama proses pemotongan, udara, lantai atau tanah, peralatan pemotongan, dan tempat pemasaran beserta peralatan dan penjualannya. Pada tempat pemotongan dan alat-alat yang digunakan jika tidak bersih (higienis) akan mempengaruhi jumlah kontaminasi mikroba ke karkas yang dihasilkan. Selain itu 
Tabel 6. Identifikasi bahaya dalam setiap tahap pembuatan se'i di depot $\mathrm{X}$ dan $\mathrm{Y}$ serta jenis pengendalian yang dapat diterapkan

\begin{tabular}{|c|c|c|c|c|}
\hline \multirow[t]{2}{*}{ Tahapan } & \multicolumn{3}{|c|}{$\begin{array}{c}\text { Kategori } \\
\text { Bahava }\end{array}$} & \multirow[t]{2}{*}{ Tindakan Pencegahan } \\
\hline & & $\mathrm{S} \quad \mathrm{T}$ & $\mathrm{ST}$ & \\
\hline \multirow[t]{2}{*}{$\begin{array}{l}\text { Pemilihan Bahan } \\
\text { Baku Daging }\end{array}$} & $\begin{array}{l}\text { 1. Resiko kontaminasi } \\
\text { E.coli, TPC dan } \\
\text { S.aureus lingkungan } \\
\text { dan penjual daging. }\end{array}$ & $\sqrt{ }$ & & $\begin{array}{l}\text { Memilih daging yang bersih, } \\
\text { bebas dari kotoran/feses, } \\
\text { memilih tempat pemotongan } \\
\text { yang bersih. }\end{array}$ \\
\hline & $\begin{array}{l}\text { 2. Daging yang dibeli dari } \\
\text { peternak }\end{array}$ & $\sqrt{ }$ & & $\begin{array}{l}\text { Pengetahuan tentang ciri-ciri } \\
\text { daging yang berasal dari babi } \\
\text { sakit atau babi sehat. }\end{array}$ \\
\hline \multirow[t]{2}{*}{$\begin{array}{l}\text { Pengirisan, curing } \\
\text { dan pencampuran } \\
\text { Bumbu }\end{array}$} & $\begin{array}{l}\text { 1. Kontaminasi dari } \\
\text { pekerja yang tidak } \\
\text { menggunakan sarung } \\
\text { tangan. }\end{array}$ & $\sqrt{ }$ & & $\begin{array}{l}\text { Pekerja sebaiknya diwajibkan } \\
\text { dan diberikan alat pelindung } \\
\text { diri (APD) lengkap. }\end{array}$ \\
\hline & $\begin{array}{l}\text { 2. Kontaminasi alat yang } \\
\text { digunakan }\end{array}$ & $\sqrt{ }$ & & $\begin{array}{l}\text { Pengecekan dan pembersihan/ } \\
\text { sterilisasi alat yang akan } \\
\text { digunakan }\end{array}$ \\
\hline \multirow[t]{2}{*}{$\begin{array}{l}\text { P e n g a s a p a n } \\
\text { daging } s e^{\prime} i\end{array}$} & $\begin{array}{l}\text { 1. Pekerja tidak } \\
\text { menggunakan alat } \\
\text { pelindung diri (APD). }\end{array}$ & $\sqrt{ }$ & & $\begin{array}{l}\text { Pekerja sebaiknya diwajibkan } \\
\text { dan diberikan alat pelindung } \\
\text { diri (APD) lengkap. }\end{array}$ \\
\hline & $\begin{array}{l}\text { 2. Bakteri patogen } \\
\text { seperti E.coli dan } \\
\text { Staphylococcus aureus } \\
\text { tidak mati apabila tidak } \\
\text { dipanaskan dengan } \\
\text { benar }\end{array}$ & $\sqrt{ }$ & & $\begin{array}{l}\text { Jarak bara kayu dengan para- } \\
\text { para tempat meletakan daging } \\
\text { sekitar } 50-100 \mathrm{~cm} \text { lama proses } \\
\text { pengasapan sekitar } \pm 30-45 \\
\text { menit. }\end{array}$ \\
\hline $\begin{array}{l}\text { Penyimpanan } \\
\text { daging } s e^{\prime} i\end{array}$ & $\begin{array}{l}\text { Se'i yang langsung dijual } \\
\text { diletakkan di rak kaca } \\
\text { tanpa penutup sehingga } \\
\text { terkontaminasi udara dan } \\
\text { tempat penyimpanan. }\end{array}$ & $\sqrt{ }$ & & $\begin{array}{l}\text { Se'i yang langsung dijual } \\
\text { disimpan dalam wada yang } \\
\text { tertutup agar mikroorganisme } \\
\text { tidak berkembang. }\end{array}$ \\
\hline
\end{tabular}

Keterangan: S: Sedang, T: Tinggi, ST: Sangat Tinggi

kebersihan alat transportasi sangat penting dalam menjamin keamanan daging sebelum dikonsumsi oleh masyarakat. Transportasi yang baik memiliki bak tertutup, adanya sistem pendingin dan higienis (Dengen, 2015).

Bakteri $E$. coli daging segar dan daging $S e^{\prime} i$ pada Depot $X$ dan $Y$ yang ada di Kota Kupang

Seluruh sampel (100\%) dari dua depot se'i (X dan Y) yang ada di Kota Kupang telah terkontaminasi bakteri E.coli melebihi batas maksimal cemaran yang ditetapkan oleh SNI (2009) yaitu < 3/g (Tabel 7). Jumlah bakteri E.coli daging segar yang tertinggi untuk depot $X$ (sampel 1, 2, dan 3) yaitu sebesar 9,2g dan depot Y (sampel 3) yaitu sebesar 3,6 g. Sedangkan untuk daging se'i, jumlah bakteri E.coli untuk depot X dan depot Y yaitu sebesar 3,6g.

KontaminasiyangtinggidariEscherichia coli pada daging se'i berhubungan erat dengan rendahnya kesadaran akan kebersihan 
Tabel 7. Proporsi TPC, E. coli, dan S. aureus daging segar dan daging se'i di X dan Y yang ada di Kota Kupang

\begin{tabular}{cccccccc}
\hline & \multicolumn{6}{c}{ Uji (Cfu/g) } \\
\cline { 3 - 7 } Depot $s e^{\prime} i$ & \multirow{2}{*}{ Sampel } & \multicolumn{2}{c}{ TPC } & \multicolumn{2}{c}{ E. coli aureus } \\
\cline { 2 - 7 } & & Segar & $S e^{\prime} i$ & Segar & $S e^{\prime} i$ & Segar & Se' \\
\hline $\mathrm{X}$ & 1 & $2,0 \times 10^{5}$ & $7,6 \times 10^{5}$ & 9,2 & 3,6 & 8 & 0 \\
& 2 & $1,2 \times 10^{7}$ & $1,9 \times 10^{5}$ & 9,2 & 3,6 & 3 & 0 \\
& 3 & $6,1 \times 10^{5}$ & $9,1 \times 10^{4}$ & 9,2 & 3,6 & 2 & 0 \\
& 4 & $8,8 \times 10^{6}$ & $1,6 \times 10^{5}$ & $<3,6$ & 3,6 & 9 & 0 \\
\hline $\mathrm{Y}$ & 1 & $7,2 \times 10^{7}$ & $9,2 \times 10^{3}$ & $<3,6$ & 3,6 & 0 & 8 \\
& 2 & $6,7 \times 10^{6}$ & $9,5 \times 10^{3}$ & 3,0 & 3,6 & 11 & 0 \\
& 3 & $5,9 \times 10^{6}$ & $1,2 \times 10^{4}$ & 3,6 & 3,6 & 11 & 0 \\
& 4 & $6,5 \times 10^{6}$ & $1,5 \times 10^{4}$ & $<3,6$ & 3,6 & 1 & 8 \\
\hline
\end{tabular}

sanitasi dan higienis bahan dan pekerja dalam proses pengolahan dan penanganan terhadap daging. Persyaratan higiene sangat penting dalam proses pengolahan $s e ' i$, antara lain kebersihan bangunan, pekerja, perlengkapan, dan peralatan yang digunakan, agar tidak menjadi sumber kontaminasi pada proses pengolahan daging $s e^{\prime} i$. Hal ini sesuai dengan kenyataan di lapangan bahwa dalam proses pengolahan daging dari awal hingga akhir tidak memperhatikan faktor hygiene, baik pekerja maupun bahan dan peralatan yang digunakan. Abubakar (2003) bahwa Dalam menghasilkan daging ayam, produsen dan pengolah diharapkan dapat menerapkan cara-cara berproduksi yang baik atau Good Manufacture Practices (GMP) dan penerapan sistem keamanan pangan atau HACCP, sehingga daging ayam yang dihasilkan aman dan sehat dikonsumsi (Abubakar, 2003).

\section{Bakteri $S$. aureus daging segar dan daging $S e$ ' $i$ pada Depot $X$ dan Y yang ada di Kota Kupang}

Pada depot X, jumlah bakteri Staphylococcus aureus untuk daging segar yang tertinggi yaitu 9 koloni/g (sampel 4) sedangkan pada se' $i$ semua sampel nilainya negatif (Tabel 7). Sedangkan pada depot Y, bakteri Staphylococcus aureus untuk daging segar yang tertinggi yaitu $11 \mathrm{koloni} / \mathrm{g}$ (sampel 2 dan 3) sedangkan pada se'i, angka tertingginya yaitu 8 (sampel 1 dan 4). Bila di bandingkan dengan kontaminasi bakteri Staphylococcus aureus menurut SNI (2009) maka cemaran bakteri Staphylococcus aureus pada daging segar dan se' $i$ di dua depot (X dan Y) masih dalam batas normal yaitu di bawah dari $1 \times 10^{2}$ koloni $/ \mathrm{g}$.

\section{Kadar Nitrit daging segar dan daging se' $i$}

Kadar Nitrit pada seluruh sampel dari dua depot se'i (X dan Y) yang ada di Kota Kupang masih dalam batas normal (Tabel 8). Menurut peraturan Menteri Kesehatan RI nomor 722/Menkes/Per/IX/88 tentang bahan tambahan makanan menyatakan bahwa kadar nitrit yang diijinkan pada produk akhir daging olahan adalah $200 \mathrm{mg} / \mathrm{kg}$ bahan. Sedangkan USDA (United States Departement of Agriculture) membatasi penggunaan maksimum nitrit sebagai garam sodium atau potasium yaitu $239,7 \mathrm{~g} / 100 \mathrm{~L}$ larutan garam, $62,8 \mathrm{~g} / 100 \mathrm{~kg}$ daging untuk daging kering atau $15,7 \mathrm{~g} / 100 \mathrm{~kg}$ daging cacahan untuk sosis (Diana, 2012).

Hasil penelitian ini sesuai dengan pengamatan di lapangan bahwa dari dua depot yang ada, ditemukan satu sampel pada depot $X$ yang kadar nitritnya melebihi batas yang telah ditentukan oleh Menteri Kesehatan RI nomor 722/Menkes/Per/IX/88. Hal ini dikarenakan dalam penambahan saltpeter (nitrit) pada proses pembuatan se' $i$, takaran saltpeter 
Tabel 8. Proporsi $\mathrm{Pb}$ dan $\mathrm{Mn}$ daging segar dan daging se'i di depot $\mathrm{X}$ dan $\mathrm{Y}$

\begin{tabular}{cccccccc}
\hline \multirow{2}{*}{$\begin{array}{c}\text { Depot } \\
s e^{\prime} i\end{array}$} & \multirow{2}{*}{ Sampel } & \multicolumn{2}{c}{ Nitrit $(\mathrm{mg} / \mathrm{kg})$} & \multicolumn{2}{c}{$\mathrm{Pb}(\mathrm{mg} / \mathrm{kg})$} & \multicolumn{2}{c}{$\mathrm{Mn}(\mathrm{mg} / \mathrm{kg})$} \\
\cline { 2 - 8 } & & Segar & $S e^{\prime} i$ & Segar & $S e^{\prime} i$ & Segar & $S e^{\prime} i$ \\
\hline $\mathrm{X}$ & 1 & 78,69 & 25,64 & 0,05 & 0,03 & 0,277 & $-0,273$ \\
& 2 & 45,37 & 37,41 & 0,13 & 0,18 & 0,125 & 0,130 \\
& 3 & 137,89 & 36,14 & 0,09 & 0,16 & 0,061 & 0,145 \\
& 4 & 60,95 & 64,03 & 0,09 & 0,12 & 0,087 & 0,094 \\
\hline $\mathrm{Y}$ & 1 & 39,35 & 67,28 & 0,03 & 0,07 & $-0,279$ & $-0,276$ \\
& 2 & 32,52 & 121,46 & 0,13 & 0,15 & 0,061 & 0,072 \\
& 3 & 98,06 & 246,15 & 0,10 & 0,12 & 0,065 & 0,088 \\
& 4 & 36,32 & 39,95 & 0,09 & 0,10 & 0,044 & 0,043 \\
\hline
\end{tabular}

yang digunakan tidak mempunyai ukuran yang tetap. Salah satu keamanan pangan yang perlu diperhatikan adalah penggunaan bahan pengawet. Bahan pengawet yang biasa digunakan dalam proses curing daging adalah garam nitrit dan nitrat. Garam nitrit dan nitrat digunakan dalam proses curing daging untuk memperoleh warna yang baik dan mencegah pertumbuhan mikroba seperti Clostridium botulinum. Penggunaan bahan ini semakin luas karena manfaat nitrit dalam pengolahan daging selain sebagai pembentuk warna dan bahan pengawet, juga sebagai pembentuk faktor rangsangan yaitu aroma dan cita rasa (Cahyadi, 2009).

\section{Kadar $\mathrm{Pb}$ daging segar dan daging se'i pada Depot $X$ dan $Y$ yang ada di Kota Kupang.}

Cemaran $\mathrm{Pb}$ pada daging yang ada pada depot $\mathrm{X}$ dan depot $\mathrm{Y}$ masih dalam kisaran normal. Menurut badan SNI (2009), batas cemaran $\mathrm{Pb}$ dalam daging dan hasil olahannya adalah $1,0 \mathrm{mg} / \mathrm{kg}$ (Tabel 8).

\section{KESIMPULAN}

1. Bila dilihat dari segi mikrobiologis, maka depot $\mathrm{X}$ dan $\mathrm{Y}$ memiliki cemaran mikrobiologis (TPC, E. Coli dan $S$. Aureus) yang tinggi. Hal ini berarti kedua depot tersebut belum menerapkan HACCP pada proses pengolahan daging $s e$ 'i. Bila dilihat dari segi kimia maka kandungan Nitrit pada kedua depot tersebut masih dalam kisaran normal dan bila ditinjau dari segi paparan logam berat maka cemaran timbal dan mangan pada depot $\mathrm{X}$ dan $\mathrm{Y}$ juga masih dalam taraf normal.

2. Dalam membuat suatu konsep pengendalian mutu suatu produk perlu memperhatikan: Program prasyarat, deskripsi produk, diagram alir, identifikasi bahaya (mikrobiologi, kimia dan cemaran logam berat), penetapan titik kendali kritis atau CCP, dan peta batas kritis.

\section{DAFTAR PUSTAKA}

Abubakar. 2003 Mutu Karkas Ayam Hasil Pemotongan Tradisional dan Penerapan Sistem Hazard Analysis Critical Control Point. Bogor: Balai Penelitian Ternak, hal 2

Badan Standarisasi Nasional. 1998. Standar Nasional Indonesia 4852:1998. Sistem Analisa Bahaya dan Pengendalian Titik Kritis (Hazard Analysis Critical Control Point-HACCP) serta Pedoman Penerapannya, Jakarta.

Badan Standarisasi Nasional. 2009. Standar Nasional Indonesia 7388:2009. Batas Maksimum Cemaran Mikroba dalam Pangan, Jakarta.

Badan Standarisasi Nasional. 2008. Standar Nasional Indonesia 2897:2008. Matode 
Pengujian Cemaran Mikroba dalam Daging, Telur, Susu dan Olahan, Jakarta.

Badan Standarisasi Nasional. 2006. Standar Nasional Indonesia 01-2332-2006. Cara Uji Mikrobiologi Bagian 1: Penentuan Coliform dan Eschericia coli Pada Produk Perikanan, Jakarta.

Cahyadi, W. 2009. Analisis dan Aspek Kesehatan Bahan Tambahan Pangan. PT Bumi Aksara: Jakarta.

Costa, W. Y. 2013. Daging Se'i Sapi Jurnal. http:// www. diakses 7 September 2017.

Dengen, P. R. 2015. perbandingan uji pembusukan dengan menggunakan metode uji postma, uji eber, uji $\mathrm{H}_{2} \mathrm{~S}$ dan pengujian mikroorganisme pada daging babi di pasar tradisional sentral Makassar. Skripsi. Program Studi Kedokteran Hewan. Fakultas kedokteran. Universitas Hasanuddin, Makasar.

Diana. 2012. Sistem Informasi Kesehatan. Jakarta.

Kementrian Perindustrian RI. 2010. Peraturan Menteri Perindustrian Republik Indonesia Tentang Pedoman Cara Produksi Pangan Olahan yang Baik (Good Manufacturing Practices). Nomor: 75/M-IND/PER/7/2012.

Kohar, I. 2005. Studi Kandungan Logam $\mathrm{Pb}$ dalam Tanaman Kangkung Umur 3 dan 6 Minggu Yang Ditanam di Media Yang Mengandung $\mathrm{Pb}$. Jurnal Makara Sains. 9 (2): 56-59.

Lukman, D.W. 2010. Nilai pH Daging. Bagian Kesehatan Masyarakat. Fakultas Kedokteran Hewan Institut Pertanian Bogor.

Lutfi. 2014. Uji Karakteristik Fisik dan kimia Pada Buah Stroberi (Fagria L) dengan Pembekuan Cepat Menggunakan Metode pencelupan pada Nitrogen Cair. Malang Fakultas Teknologi Pertanian Universitas Brawijaya.

Malelak, G. E. M., H. J. D. Lalel., P. R.
Kale, dan I. G. N. Jelantik. 2017. The Sensory Properties, Color, Microbial, Lipid Oxidation, and Residual Nitrite of Se'i Marinated with lime and Roselle Calyces Extracts. Med. Pet. 40 (3):194-201. https//doi.org/5398/ medpet.2017.40.3.194.

Malelak, G. E. M., G. M. Sipahelut, I. G. N. Jelantik, M. R. Denoratu, dan H. J. D. Lalel. 2015. Characteristic of se' $i$ (rotenesse smoked meat) treated with coconut shell liquid smoked and lime extract. Med. Pet. 38: 89-94. https:// doi.org/10.5398/medpet.2015.38.2.89.

Nurmawati. 2012. Proses Pembentukan Pola Perilaku Kerja Karyawan PT. Indopherin Jaya Melalui Budaya Organisasi 5S (Studi Kasus Pada Karyawan PT. Indopherin Jaya, Kota Probolinggo). Skripsi. Universitas Brawijaya, Malang.

Habibah, N. 2018. Analisis Kuantitatif Kadar Nitrit Dalam Produk Daging Olahan Di Wilayah Denpasar Dengan Metode Griess Secara Spektofotometri. International Journal of Natural Science and Enginering. Jurusan Analis Kesehatan Politeknik Kesehatan Kemenkes Denpasar, Bali. 2 (1): 1-9.

Prasetyo, A.T. 2000. Implementasi GMP dan HACCP dalam Menunjang Quality Assurance Industri Pangan.Skripsi. Universitas Brawijaya, Malang

Bahri, S. 2008. Beberapa aspek keamanan pangan asal ternak di Indonesia, Pengembangan Inovasi, Balai besar penelitian Veteriner, Bogor.

Suardana, I. W dan I. B. N. Swacita. 2009. Higiene Makanan Kajian Teori dan Prinsip Dasar. Udayana University Press, Denpasar.

Thaheer, H. 2005. Sistem Manajemen HACCP. Bumi Aksara, Jakarta.

Usmiati, S. 2010. Pengawetan Daging Segar dan Olahan. Bogor: Balai Besar Penelitian dan Pengembangan Pascapanen Pertanian. 